NBER WORKING PAPER SERIES

\title{
CLOSING SMALL OPEN ECONOMY MODELS
}

\author{
Stephanie Schmitt-Grohé \\ Martín Uribe \\ Working Paper 9270 \\ http://www.nber.org/papers/w9270 \\ NATIONAL BUREAU OF ECONOMIC RESEARCH \\ 1050 Massachusetts Avenue \\ Cambridge, MA 02138 \\ October 2002
}

The views expressed herein are those of the authors and not necessarily those of the National Bureau of Economic Research.

(C) 2002 by Stephanie Schmitt-Grohé and Martín Uribe. All rights reserved. Short sections of text, not to exceed two paragraphs, may be quoted without explicit permission provided that full credit, including (C) notice, is given to the source. 
Closing Small Open Economy Models

Stephanie Schmitt-Grohé and Martín Uribe

NBER Working Paper No. 9270

October 2002

JEL No. F41

\section{$\underline{\text { ABSTRACT }}$}

The small open economy model with incomplete asset markets features a steady state that depends on initial conditions and equilibrium dynamics that possess a random walk component. A number of modifications to the standard model have been proposed to induce stationarity. This paper presents a quantitative comparison of these alternative approaches. Five different specifications are considered: (1) A model with an endogenous discount factor (Uzawa-type preferences); (2) A model with a debt-elastic interest-rate premium; (3) A model with convex portfolio adjustment costs; (4) A model with complete asset markets; and (5) A model without stationarity-inducing features. The main finding of the paper is that all models deliver virtually identical dynamics at business-cycle frequencies, as measured by unconditional second moments and impulse response functions. The only noticeable difference among the alternative specifications is that the complete-asset-market model induces smoother consumption dynamics.

Stephanie Schmitt-Grohé

Department of Economics

Rutgers University

New Brunswick, NJ 08901

CEPR and NBER

grohe@econ.rutgers.edu
Martín Uribe

Department of Economics

University of Pennsylvania

Philadelphia, PA 19104

and NBER

uribe@econ.upenn.edu 


\section{Introduction}

Computing business-cycle dynamics in the standard small open economy model is problematic. In this model, domestic residents have only access to a risk-free bond whose rate of return is exogenously determined abroad. As a consequence, the steady state of the model depends on initial conditions. In particular, it depends upon the country's initial net foreign asset position. ${ }^{1}$ Put differently, transient shocks have long-run effects on the state of the economy. That is, the equilibrium dynamics posses a random walk component. The random walk property of the dynamics implies that the unconditional variance of variables such as asset holdings and consumption is infinite. Thus, endogenous variables in general wonder around an infinitely large region in response to bounded shocks. This introduces serious computational difficulties because all available techniques are valid locally around a given stationary path.

To resolve this problem, researchers resort to a number of modifications to the standard model that have no other purpose than to induce stationarity of the equilibrium dynamics. Obviously, because these modifications basically remove the built-in random walk property of the canonical model, they all necessarily alter the low-frequency properties of the model. The focus of the present study is to assess the extent to which these stationarity-inducing techniques affect the equilibrium dynamics at business-cycle frequencies.

We compare the business-cycle properties of five variations of the small open economy. In section 2 we consider a model with an endogenous discount factor (Uzawa (1968) type preferences). Recent papers using this type of preferences include Obstfeld (1990), Mendoza (1991), SchmittGrohé (1998), and Uribe (1997). In this model, the subjective discount factor, typically denoted by $\beta$, is assumed to be decreasing in consumption. Agents become more impatient the more they consume. The reason why this modification makes the steady state independent of initial conditions becomes clear from inspection of the Euler equation $\lambda_{t}=\beta\left(c_{t}\right)(1+r) \lambda_{t+1}$. Here, $\lambda_{t}$ denotes the marginal utility of wealth, and $r$ denotes the world interest rate. In the steady state, this equation reduces to $\beta(c)(1+r)=1$, which pins down the steady-state level of consumption solely as a function of $r$ and the parameters defining the function $\beta(\cdot)$. Kim and Kose (2001) compare the business-cycle implications of this model to those implied by a model with a constant discount factor. They find that both models feature similar comovements of macroeconomic aggregates. We also consider a simplified specification of Uzawa preferences where the discount factor is assumed to be a function of aggregate per capita consumption rather than individual consumption. This specification is arguably no more arbitrary than the original Uzawa specification and has a number of advantages. First, it also induces stationarity since the above Euler equation still holds. Second, the modified Uzawa preferences result in a model that is computationally much simpler than the standard Uzawa model, for it contains one less Euler equation and one less Lagrange multiplier. Finally, the quantitative predictions of the modified Uzawa model are not significantly different from those of the original model.

In section 3 we study a model with a debt-elastic interest-rate premium. This stationarity inducing technique has been used, among others, in recent papers by Senhadji (1994), Mendoza and Uribe (2000), and Schmitt-Grohé and Uribe (2001). In this model, domestic agents are assumed to face an interest rate that is increasing in the country's net foreign debt. To see why this device induces stationarity, let $p\left(d_{t}\right)$ denote the premium over the world interest rate paid by domestic residents, and $d_{t}$ the stock of foreign debt. Then in the steady state the Euler equation implies that $\beta[1+r+p(d)]=1$. This expression determines the steady-state net foreign asset position as

\footnotetext{
${ }^{1}$ If the real rate of return on the foreign bond exceeds (is less than) the subjective rate of discount, the model displays perpetual positive (negative) growth. It is standard to eliminate this source of dynamics by assuming that the subjective discount rate equals the (average) real interest rate.
} 
a function of $r$ and the parameters that define the premium function $p(\cdot)$ only.

Section 4 features a model with convex portfolio adjustment costs. This way of ensuring stationarity has recently been used by Neumeyer and Perri (2001). In this model, the cost of increasing asset holdings by one unit is greater than one because it includes the marginal cost of adjusting the size of the portfolio. The Euler equation thus becomes $\lambda_{t}\left[1+\psi^{\prime}\left(d_{t}\right)\right]=\beta(1+r) \lambda_{t+1}$, where $\psi(\cdot)$ is the portfolio adjustment cost. In the steady state, this expression simplifies to $1+\psi^{\prime}(d)=\beta(1+r)$, which implies a steady-state level of foreign debt that depends only on parameters of the model.

The models discussed thus far all feature incomplete asset markets. Section 5 presents a model of a small open economy with complete asset markets. Under complete asset markets, the marginal utility of consumption is proportional across countries. So one equilibrium condition states that $U_{c}\left(c_{t}\right)=\alpha U^{*}\left(c_{t}^{*}\right)$, where $U$ denotes the period utility function and stars are used to denote foreign variables. Because the domestic economy is small, $c_{t}^{*}$ is determined exogenously. Thus, stationarity of $c_{t}^{*}$ implies stationarity of $c_{t}$.

For the purpose of comparison, in section 6 we also study the dynamics of the standard small open economy model without any type of stationarity-inducing features, such as the economy analyzed in Correia et al. (1995). In this economy, the equilibrium levels of consumption and net foreign assets display a unit root. As a result unconditional second moments are not well defined. For this reason, we limit the numerical characterization of this model to impulse response functions.

All models are calibrated in such a way that they predict identical steady states. The functional forms of preferences and technologies are also identical across models. The basic calibration and parameterization is taken from Mendoza (1991). The business-cycle implications of the alternative models are measured by second moments and impulse responses. The central result of the paper is that all models with incomplete asset markets deliver virtually identical dynamics at businesscycle frequencies. The complete-asset-market model induces smoother consumption dynamics but similar implications for hours and investment.

Section ?? presents a sensitivity analysis. It shows that the main results of the paper are robust to alternative preference specifications. In addition, it explores the relationship between the magnitude of the parameters determining stationarity and the speed of convergence to the long-run equilibrium.

\section{Model 1: Endogenous Discount Factor}

Consider a small open economy populated by a large number of identical households with preferences described by the following utility function:

$$
\begin{gathered}
E_{0} \sum_{t=0}^{\infty} \theta_{t} U\left(c_{t}, h_{t}\right), \\
\theta_{0}=1, \\
\theta_{t+1}=\beta\left(c_{t}, h_{t}\right) \theta_{t} \quad t \geq 0,
\end{gathered}
$$

where $\beta_{c}<0, \beta_{h}>0$. This preference specification allows the model to be stationary, in the sense that the non-stochastic steady state is independent of initial conditions (namely, the initial level of financial wealth, physical capital, and total factor productivity).

The evolution of foreign debt, $d_{t}$, is given by

$$
d_{t}=\left(1+r_{t-1}\right) d_{t-1}-y_{t}+c_{t}+i_{t}+\Phi\left(k_{t+1}-k_{t}\right)
$$


where $r_{t}$ denotes the interest rate at which domestic residents can borrow in international markets in period $t, y_{t}$ denotes domestic output, $c_{t}$ denotes consumption, $i_{t}$ denotes gross investment, and $k_{t}$ denotes physical capital. The function $\Phi(\cdot)$ is meant to capture capital adjustment costs and is assumed to satisfy $\Phi(0)=\Phi^{\prime}(0)=0$. Small open economy models typically include capital adjustment costs to avoid excessive investment volatility in response to variations in the domesticforeign interest rate differential. The restrictions imposed on $\Phi$ ensure that in the non-stochastic steady state adjustment costs are zero and the domestic interest rate equals the marginal product of capital net of depreciation. Output is produced by means of a linearly homogeneous production function that takes capital and labor services as inputs,

$$
y_{t}=A_{t} F\left(k_{t}, h_{t}\right),
$$

where $A_{t}$ is an exogenous stochastic productivity shock. The stock of capital evolves according to

$$
k_{t+1}=i_{t}+(1-\delta) k_{t},
$$

where $\delta \in(0,1)$ denotes the rate of depreciation of physical capital.

Households choose processes $\left\{c_{t}, h_{t}, y_{t}, i_{t}, k_{t+1}, d_{t}, \theta_{t+1}\right\}_{t=0}^{\infty}$ so as to maximize the utility function (1) subject to (2)-(6) and a no-Ponzi constraint of the form

$$
\lim _{j \rightarrow \infty} E_{t} \frac{d_{t+j}}{\prod_{s=1}^{j}\left(1+r_{s}\right)} \leq 0
$$

Letting $\theta_{t} \eta_{t}$ and $\lambda_{t}$ denote the Lagrange multipliers on (3) and (4), the first-order conditions of the household's maximization problem are (3)-(7) holding with equality and:

$$
\begin{gathered}
\lambda_{t}=\beta\left(c_{t}, h_{t}\right)\left(1+r_{t}\right) E_{t} \lambda_{t+1} \\
\lambda_{t}=U_{c}\left(c_{t}, h_{t}\right)-\eta_{t} \beta_{c}\left(c_{t}, h_{t}\right) \\
\eta_{t}=-E_{t} U\left(c_{t+1}, h_{t+1}\right)+E_{t} \eta_{t+1} \beta\left(c_{t+1}, h_{t+1}\right) \\
-U_{h}\left(c_{t}, h_{t}\right)+\eta_{t} \beta_{h}\left(c_{t}, h_{t}\right)=\lambda_{t} A_{t} F_{h}\left(k_{t}, h_{t}\right) \\
\lambda_{t}\left[1+\Phi^{\prime}\left(k_{t+1}-k_{t}\right)\right]=\beta\left(c_{t}, h_{t}\right) E_{t} \lambda_{t+1}\left[A_{t+1} F_{k}\left(k_{t+1}, h_{t+1}\right)+1-\delta+\Phi^{\prime}\left(k_{t+2}-k_{t+1}\right)\right]
\end{gathered}
$$

These first-order conditions are fairly standard, except for the fact that the marginal utility of consumption is not given simply by $U_{c}\left(c_{t}, h_{t}\right)$ but rather by $U_{c}\left(c_{t}, h_{t}\right)-\beta_{c}\left(c_{t}, h_{t}\right) \eta_{t}$. The second term in this expression reflects the fact that an increase in current consumption lowers the discount factor $\left(\beta_{c}<0\right)$. In turn, a unit decline in the discount factor reduces utility in period $t$ by $\eta_{t}$. Intuitively, $\eta_{t}$ equals the present discounted value of utility from period $t+1$ onward. To see this, iterate the first-order condition (10) forward to obtain: $\eta_{t}=-E_{t} \sum_{j=1}^{\infty}\left(\frac{\theta_{t+j}}{\theta_{t+1}}\right) U\left(c_{t+j}, h_{t+j}\right)$. Similarly, the marginal disutility of labor is not simply $U_{h}\left(c_{t}, h_{t}\right)$ but instead $U_{h}\left(c_{t}, h_{t}\right)-\beta_{h}\left(c_{t}, h_{t}\right) \eta_{t}$.

In this model, the interest rate faced by domestic agents in world financial markets is assumed to be constant and given by

$$
r_{t}=r .
$$

The law of motion of the productivity shock is given by:

$$
\ln A_{t+1}=\rho \ln A_{t}+\epsilon_{t+1} ; \quad \epsilon_{t+1} \sim \operatorname{NIID}\left(0, \sigma_{\epsilon}^{2}\right) ; \quad t \geq 0 .
$$

A competitive equilibrium is a set of processes $\left\{d_{t}, c_{t}, h_{t}, y_{t}, i_{t}, k_{t+1}, \eta_{t}, \lambda_{t}\right\}$ satisfying (4)-(12) all holding with equality, given (13), (14), $A_{0}, d_{-1}$, and $k_{0}$. 
We parameterize the model following Mendoza (1991), who uses the following functional forms for preferences and technology:

$$
\begin{gathered}
U(c, h)=\frac{\left[c-\omega^{-1} h^{\omega}\right]^{1-\gamma}-1}{1-\gamma} \\
\beta(c, h)=\left[1+c-\omega^{-1} h^{\omega}\right]^{-\psi_{1}} \\
F(k, h)=k^{\alpha} h^{1-\alpha} \\
\Phi(x)=\frac{\phi}{2} x^{2} ; \quad \phi>0 .
\end{gathered}
$$

As is well known, the functional forms of the period utility function and the discount factor imply that the marginal rate of substitution between consumption and leisure depends only on labor. In effect, combining equations (9) and (11) yields

$$
h_{t}^{\omega-1}=A_{t} F_{h}\left(k_{t}, h_{t}\right)
$$

The right-hand side of this expression is the marginal product of labor, which in equilibrium equals the real wage rate. The left-hand side is the marginal rate of substitution of leisure for consumption. The above expression thus states that the labor supply depends only upon the wage rate and in particular that it is independent of the level of wealth.

We also follow Mendoza (1991) in assigning values to the structural parameters of the model. Mendoza calibrates the model to the Canadian economy. The time unit is meant to be a year. The parameter values are shown on table 1. All parameter values are standard in the real-business-

Table 1: Model 1: Calibration

\begin{tabular}{|c|c|c|c|c|c|c|c|c|}
\hline$\gamma$ & $\omega$ & $\psi_{1}$ & $\alpha$ & $\phi$ & $r$ & $\delta$ & $\rho$ & $\sigma_{\epsilon}$ \\
\hline 2 & 1.455 & .11 & .32 & 0.028 & 0.04 & 0.1 & 0.42 & 0.0129 \\
\hline
\end{tabular}

cycle literature. It is of interest to review the calibration of the parameter $\psi_{1}$ defining the elasticity of the discount factor with respect to the composite $c-h^{\omega} / \omega$. Given the focus of our paper, this parameter is important because it determines the stationarity of the model and the speed of convergence to the steady state. The value assigned to $\psi_{1}$ is set so as to match the average Canadian trade-balance-to-GDP ratio. To see how in steady state this ratio is linked to the value of $\psi_{1}$, use equation (12) in steady state to get

$$
\frac{h}{k}=\left(\frac{r+\delta}{\alpha}\right)^{\frac{1}{1-\alpha}}
$$

It follows from this expression that the steady-state capital-labor ratio is independent of the parameter $\psi_{1}$. Given the capital-labor ratio, equilibrium condition (15) implies that the steady-state value of hours is also independent of $\psi_{1}$ and given by

$$
h=\left[(1-\alpha)\left(\frac{\alpha}{r+\delta}\right)^{\frac{\alpha}{1-\alpha}}\right]^{\frac{1}{\omega-1}}
$$

Given the steady-state values of hours and the capital-labor ratio, we can find directly the steadystate values of capital, investment $(i=\delta k)$, and output $\left(k^{\alpha} h^{1-\alpha}\right)$, independently of $\psi_{1}$. Now note 
that in the steady state the trade-balance-to-GDP ratio, $t b / F(k, h)$, is given by $1-(c+i) / F(k, h)$. Then, equilibrium condition (8) implies the following steady state condition relating the tradebalance-to-GDP ratio to $\psi_{1}: \beta(F(k, h)-t b-i, h)(1+r)=1$. Using the specific functional form for the discount factor, this expression can be written as:

$$
\frac{t b}{F(k, h)}=1-\frac{i}{F(k, h)}-\frac{\left[(1+r)^{1 / \psi_{1}}+\frac{h^{\omega}}{\omega}-1\right]}{F(k, h)}
$$

This expression can be solved for $\psi_{1}$ given $t b / F(k, h), \alpha, r, \delta$, and $\omega$. All other things constant, the larger is the trade-balance-to-output ratio the larger is the required value of $\psi_{1}$.

\subsection{Model 1a: Endogenous Discount Factor Without Internalization}

Consider an alternative formulation of the endogenous discount factor model where domestic agents do not internalize the fact that their discount factor depends on their own levels of consumption and effort. Alternatively, suppose that the discount factor depends not upon the agent's own consumption and effort, but rather on the average per capita levels of these variables. Formally, preferences are described by (1), (2), and

$$
\theta_{t+1}=\beta\left(\tilde{c}_{t}, \tilde{h}_{t}\right) \theta_{t} \quad t \geq 0
$$

where $\tilde{c}_{t}$ and $\tilde{h}_{t}$ denote average per capital consumption and hours, which the individual household takes as given.

The first-order conditions of the household's maximization problem are (2), (4)-(7), (16) holding with equality and:

$$
\begin{gathered}
\lambda_{t}=\beta\left(\tilde{c}_{t}, \tilde{h}_{t}\right)\left(1+r_{t}\right) E_{t} \lambda_{t+1} \\
\lambda_{t}=U_{c}\left(c_{t}, h_{t}\right) \\
-U_{h}\left(c_{t}, h_{t}\right)=\lambda_{t} A_{t} F_{h}\left(k_{t}, h_{t}\right) \\
\lambda_{t}\left[1+\Phi^{\prime}\left(k_{t+1}-k_{t}\right)\right]=\beta\left(\tilde{c}_{t}, \tilde{h}_{t}\right) E_{t} \lambda_{t+1}\left[A_{t+1} F_{k}\left(k_{t+1}, h_{t+1}\right)+1-\delta+\Phi^{\prime}\left(k_{t+2}-k_{t+1}\right)\right]
\end{gathered}
$$

In equilibrium, individual and average per capita variables are identical. That is,

$$
\begin{aligned}
c_{t} & =\tilde{c}_{t} \\
h_{t} & =\tilde{h}_{t}
\end{aligned}
$$

A competitive equilibrium is a set of processes $\left\{d_{t}, c_{t}, h_{t}, \tilde{c}_{t}, \tilde{h}_{t}, y_{t}, i_{t}, k_{t+1}, \lambda_{t}\right\}$ satisfying (4)-(7), (17)-(22) all holding with equality, given (13), (14), $A_{0}, d_{-1}$, and $k_{0}$. Note that the equilibrium conditions include one Euler equation less, equation (10), and one state variable less, $\eta_{t}$, than the standard endogenous-discount-factor model. This feature facilitates the computation of the equilibrium dynamics.

We evaluate the model using the same functional forms and parameter values as in Model 1.

\section{Model 2: Debt Elastic Interest Rate}

In Model 2, stationarity is induced by assuming that the interest rate faced by domestic agents, $r_{t}$, is increasing in the aggregate level of foreign debt, which we denote by $\tilde{d}_{t}$. Specifically, $r_{t}$ is given by

$$
r_{t}=r+p\left(\tilde{d}_{t}\right)
$$


where $r$ denotes the world interest rate and $p(\cdot)$ is a country-specific interest rate premium. The function $p(\cdot)$ is assumed to be strictly increasing.

Preferences are given by equation (1). Unlike in the previous model, preferences are assumed to display a constant subjective rate of discount. Formally,

$$
\theta_{t}=\beta^{t}
$$

where $\beta \in(0,1)$ is a constant parameter.

The representative agent's first-order conditions are (4)-(7) holding with equality and

$$
\begin{gathered}
\lambda_{t}=\beta\left(1+r_{t}\right) E_{t} \lambda_{t+1} \\
U_{c}\left(c_{t}, h_{t}\right)=\lambda_{t} \\
-U_{h}\left(c_{t}, h_{t}\right)=\lambda_{t} A_{t} F_{h}\left(k_{t}, h_{t}\right) . \\
\lambda_{t}\left[1+\Phi^{\prime}\left(k_{t+1}-k_{t}\right)\right]=\beta E_{t} \lambda_{t+1}\left[A_{t+1} F_{k}\left(k_{t+1}, h_{t+1}\right)+1-\delta+\Phi^{\prime}\left(k_{t+2}-k_{t+1}\right)\right]
\end{gathered}
$$

Because agents are assumed to be identical, in equilibrium aggregate per capita debt equals individual debt, that is,

$$
\tilde{d}_{t}=d_{t}
$$

A competitive equilibrium is a set of processes $\left\{d_{t}, \tilde{d}_{t+1}, c_{t}, h_{t}, y_{t}, i_{t}, k_{t+1}, r_{t}, \lambda_{t}\right\}_{t=0}^{\infty}$ satisfying (4)(7), and (23)-(28) all holding with equality, given (14), $A_{0}, d_{-1}$, and $k_{0}$.

We adopt the same forms for the functions $U, F$, and $\Phi$ as in Model 1. We use the following functional form for the risk premium:

$$
p(d)=\psi_{2}\left(e^{d-\bar{d}}-1\right)
$$

where $\psi_{2}$ and $\bar{d}$ are constant parameters.

We calibrate the parameters $\gamma, \omega, \alpha, \phi, r, \delta, \rho$, and $\sigma_{\epsilon}$ using the values shown in table 1 . We set the subjective discount factor equal to the world interest rate; that is,

$$
\beta=\frac{1}{1+r} .
$$

The parameter $\bar{d}$ equals the steady-state level of foreign debt. To see this, note that in steady state, the equilibrium conditions (23) and (24) together with the assumed form of the interest-rate premium imply that $1=\beta\left[1+r+\psi_{2}\left(e^{d / \bar{d}}-1\right)\right]$. The fact that $\beta(1+r)=1$ then implies that $d=\bar{d}$. If follows that in the steady state the interest rate premium is nil. We set $\bar{d}$ so that the steady-state level of foreign debt equals the one implied by Model 1. Finally, we set the parameter $\psi_{2}$ so as to ensure that this model and Model 1 generate the same volatility in the current-accountto-GDP ratio. The resulting values of $\beta, \bar{d}$, and $\psi_{2}$ are given in table 2 .

Table 2: Model 2: Calibration of Parameters Not Shared With Model 1

\begin{tabular}{|c|c|c|}
\hline$\beta$ & $\bar{d}$ & $\psi_{2}$ \\
\hline 0.96 & 0.7442 & 0.000742 \\
\hline
\end{tabular}




\section{Model 3: Portfolio Adjustment Costs}

In this model, stationarity is induced by assuming that agents face convex costs of holding assets in quantities different from some long-run level. Preferences and technology are as in Model 2. In contrast to what is assumed in Model 2, here the interest rate at which domestic households can borrow from the rest of the world is constant and equal to the world interest, that is, equation (13) holds. The sequential budget constraint of the household is given by

$$
d_{t}=\left(1+r_{t-1}\right) d_{t-1}-y_{t}+c_{t}+i_{t}+\Phi\left(k_{t+1}-k_{t}\right)+\frac{\psi_{3}}{2}\left(d_{t}-\bar{d}\right)^{2},
$$

where $\psi_{3}$ and $\bar{d}$ are constant parameters defining the portfolio adjustment cost function. The firstorder conditions associated with the household's maximization problem are (5)-(7), (25)-(27), (29) holding with equality and

$$
\lambda_{t}\left[1-\psi_{3}\left(d_{t}-\bar{d}\right)\right]=\beta\left(1+r_{t}\right) E_{t} \lambda_{t+1}
$$

This optimality condition states that if the household chooses to borrow an additional unit, then current consumption increases by one unit minus the marginal portfolio adjustment cost $\psi_{3}\left(d_{t}-\bar{d}\right)$. The value of this increase in consumption in terms of utility is given by the left-hand side of the above equation. Next period, the household must repay the additional unit of debt plus interest. The value of this repayment in terms of today's utility is given by the right-hand side. At the optimum, the marginal benefit of a unit debt increase must equal its marginal cost.

A competitive equilibrium is a set of processes $\left\{d_{t}, c_{t}, h_{t}, y_{t}, i_{t}, k_{t+1}, r_{t}, \lambda_{t}\right\}_{t=0}^{\infty}$ satisfying (5)-(7), (13), (25)-(27), (29), and (30) all holding with equality, given (14), $A_{0}, d_{-1}$, and $k_{0}$.

Preferences and technology are parameterized as in Model 2. The parameters $\gamma, \omega, \alpha, \phi, r$, $\delta, \rho$, and $\sigma_{\epsilon}$ take the values displayed in table 1 . As in model 2, the subjective discount factor is assumed to satisfy $\beta(1+r)=1$. This assumption and equation (30) imply that the parameter $\bar{d}$ determines the steady-state level of foreign debt $(d=\bar{d})$. We calibrate $\bar{d}$ so that the steadystate level of foreign debt equals the one implied by models 1, 1a, and 2 (see table 2). Finally, we assign the value 0.00074 to $\psi_{3}$, which ensures that this model and model 1 generate the same volatility in the current-account-to-GDP ratio. This parameter value is almost identical to that assigned to $\psi_{2}$ in model 2 . This is because the log-linearized versions of models 2 and 3 are almost identical. Indeed, the models share all equilibrium conditions but the resource constraint (equations (4) and (29)), the Euler equations associated with the optimal choice of foreign bonds (equations (24) and (30)), and the interest rate faced by domestic households (equations (13) and (23)). The log-linearized versions of the resource constraints are the same in both models. The log-linear approximation to the domestic interest rate is given by $\widehat{1+r_{t}}=\psi_{2} d(1+r)^{-1} \widehat{d}_{t}$ in Model 2 and by $\widehat{1+r_{t}}=0$ in Model 3. In turn, the log-linearized versions of the Euler equation for debt are $\widehat{\lambda}_{t}=\psi_{2} d(1+r)^{-1} \widehat{d}_{t}+E_{t} \widehat{\lambda}_{t+1}$ in model 2 and $\widehat{\lambda}_{t}=\psi_{3} d \widehat{d}_{t}+E_{t} \widehat{\lambda}_{t+1}$ in Model 3. It follows that for small values of $\psi_{2}$ and $\psi_{3}$ satisfying $\psi_{2}=(1+r) \psi_{3}$ models 2 and 3 will imply similar dynamics.

\section{Model 4: Complete Asset Markets}

All model economies considered thus far feature incomplete asset markets. In those models agents have access to a single financial asset that pays a risk-free real rate of return. In the model studied in this section, agents have access to a complete array of state-contingent claims. This assumption per se induces stationarity in the equilibrium dynamics.

Preferences and technology are as in model 2. The period-by-period budget constraint of the household is given by

$$
E_{t} r_{t+1} b_{t+1}=b_{t}+y_{t}-c_{t}-i_{t}-\Phi\left(k_{t+1}-k_{t}\right)
$$


where $b_{t+1}$ denotes a random variable indicating the number of assets purchased in period $t$ to be delivered in each state of period $t+1$. The variable $r_{t+1}$ denotes the period- $t$ price of an asset that pays one unit of good in a particular state of period $t+1$ divided by the probability of occurrence of that state given information available in period $t$. Households are also subject to a no-Ponzi-game constraint of the form

$$
\lim _{j \rightarrow \infty} E_{t} q_{t+j} b_{t+j} \geq 0
$$

at all dates and under all contingencies. The variable $q_{t}$ represents the period-zero price of one unit of good to be delivered in a particular state of period $t$ divided by the probability of occurrence of that state given information available at time 0 and is given by

$$
q_{t}=r_{1} r_{2} \ldots r_{t}
$$

with $q_{0} \equiv 1$. The first-order conditions associated with the household's maximization problem are (5), (6), (25)-(27), (31), and (32) holding with equality and

$$
\lambda_{t} r_{t+1}=\beta \lambda_{t+1} \text {. }
$$

A difference between this expression and the Euler equations that arise in the models with incomplete asset markets studied in previous sections is that under complete markets in each period $t$ there is one first-order condition for each possible state in period $t+1$, whereas under incomplete markets the above Euler equation holds only in expectations.

In the rest of the world, agents have access to the same array of financial assets as in the domestic economy. Consequently, one first-order condition of the foreign household is an equation similar to (33). Letting starred letters denote foreign variables or functions, we have

$$
\lambda_{t}^{*} r_{t+1}=\beta \lambda_{t+1}^{*} .
$$

Note that we are assuming that domestic and foreign households share the same subjective discount factor. Combining the domestic and foreign Euler equations - equations (33) and (34)-yields

$$
\frac{\lambda_{t+1}}{\lambda_{t}}=\frac{\lambda_{t+1}^{*}}{\lambda_{t}^{*}}
$$

This expression holds at all dates and under all contingencies. This means that the domestic marginal utility of consumption is proportional to its foreign counterpart. Formally,

$$
\lambda_{t}=\xi \lambda_{t}^{*}
$$

where $\xi$ is a constant parameter determining differences in wealth across countries. We assume that the domestic economy is small. This means that $\lambda_{t}^{*}$ must be taken as an exogenous variable. Because we are interested only in the effects of domestic productivity shocks, we assume that $\lambda_{t}^{*}$ is constant and equal to $\lambda^{*}$, where $\lambda^{*}$ is a parameter. The above equilibrium condition then becomes

$$
\lambda_{t}=\psi_{4}
$$

where $\psi_{4} \equiv \xi \lambda^{*}$ is a constant parameter.

A competitive equilibrium is a set of processes $\left\{c_{t}, h_{t}, y_{t}, i_{t}, k_{t+1}, \lambda_{t}\right\}_{t=0}^{\infty}$ satisfying (5), (6), (25)-(27), and (35), given (14), $A_{0}$, and $k_{0}$.

The functions $U, F$, and $\Phi$ are parameterized as in the previous models. The parameters $\gamma, \beta$, $\omega, \alpha, \phi, \delta, \rho$, and $\sigma_{\epsilon}$ take the values displayed in tables 1 and 2 . The parameter $\psi_{4}$ is set so as to ensure that the steady-state level of consumption is the same in this model as in models 1 to 3 . 


\section{Model 5: The Non-Stationary Case}

For comparison with the models considered thus far, in this section we describe a version of the small open economy model that displays no stationarity. In this model (a) The discount factor is constant; (b) the interest rate at which domestic agents borrow from the rest of the world is constant (and equal to the subjective discount factor); (c) agents face no frictions in adjusting the size of their portfolios; and (d) markets are incomplete in the sense that domestic households have only access to a single risk-free international bond. This specification of the model induces a random walk component in the equilibrium marginal utility of consumption and the net foreign asset position.

A competitive equilibrium in the non-stationary model is a set of processes $\left\{d_{t}, c_{t}, h_{t}, y_{t}, i_{t}\right.$, $\left.k_{t+1}, r_{t}, \lambda_{t}\right\}_{t=0}^{\infty}$ satisfying (4)-(7), (13), and (24)-(27) all holding with equality, given (14), $A_{0}, d_{-1}$, and $k_{0}$. We calibrate the model using the parameter values displayed in tables 1 and 2 .

\section{$7 \quad$ Quantitative Results}

Table 3 displays a number of unconditional second moments of interest observed in the data and implied by models $1-4 .^{2}$ In all moments, we compute the equilibrium dynamics by solving a log-linear approximation to the set of equilibrium conditions. ${ }^{3}$ Although the focus of the paper is not to assess the models' abilities to match the data, as a reference we include in the first column of the table the observed second moments using Canadian data. As pointed out by Mendoza (1991), the small open real business cycle model captures a number of features of business cycles in Canada. Specifically, as in the data, all four models predict the following ranking of volatilities, in ascending order, consumption, output, and investment. The models also correctly predict that the components of aggregate demand and hours are procyclical, and that the correlation of the trade balance with GDP is close to zero. ${ }^{4}$ The models overestimate the procyclicality of labor. In the data the correlation between hours and output is 0.8 , whereas the models imply a perfect correlation. This implication of the models is driven by the assumed preference and technology specification. In effect, using the assumed Cobb-Douglas form of the production function we can write equation (15), which holds for all models, as $h_{t}^{\omega}=(1-\alpha) y_{t}$. Log-linearizing this expression we get $\omega \widehat{h}_{t}=\widehat{y}_{t}$, where a circumflex over a variables denotes its log-deviation from the steady-state value. It follows that $\operatorname{corr}\left(\widehat{h}_{t}, \widehat{y}_{t}\right)=1$.

The main result of this paper is that regardless of how stationarity is induced in the small open economy real business cycle model, the model's predictions regarding second moments are virtually identical. This result is evident from table 3 . The only noticeable difference arises in model 4 , the complete markets case, which as expected predicts less volatile consumption. The low volatility of consumption in the complete markets model introduces an additional difference between the predictions of this model and models 1-3. Because consumption is smoother in model 4, its role in determining the cyclicality of the trade balance is smaller. As a result, model 4 predicts that the correlation between output and the trade balance is positive, whereas models 1-3 imply that it is negative.

Figure 1 demonstrates that models 1-5 also imply virtually identical impulse response functions

\footnotetext{
${ }^{2}$ Model 5 is nonstationary, and thus does not have well defined unconditional second moments.

${ }^{3}$ The Matlab computer code used to compute the unconditional second moments and impulse response functions presented in this section is available at www.econ.upenn.edu/ uribe.

${ }^{4}$ Indeed, models 1-3 predict correctly that the trade balance is countercyclical. The correlation is so close to zero, however, that its sign does depend on the solution method employed. Mendoza, for example, approximates the solution to model 1 by discretizing the state space and finds a small but positive correlation.
} 
Figure 1: Impulse Response to a Unit Technology Shock in Models 1 - 5
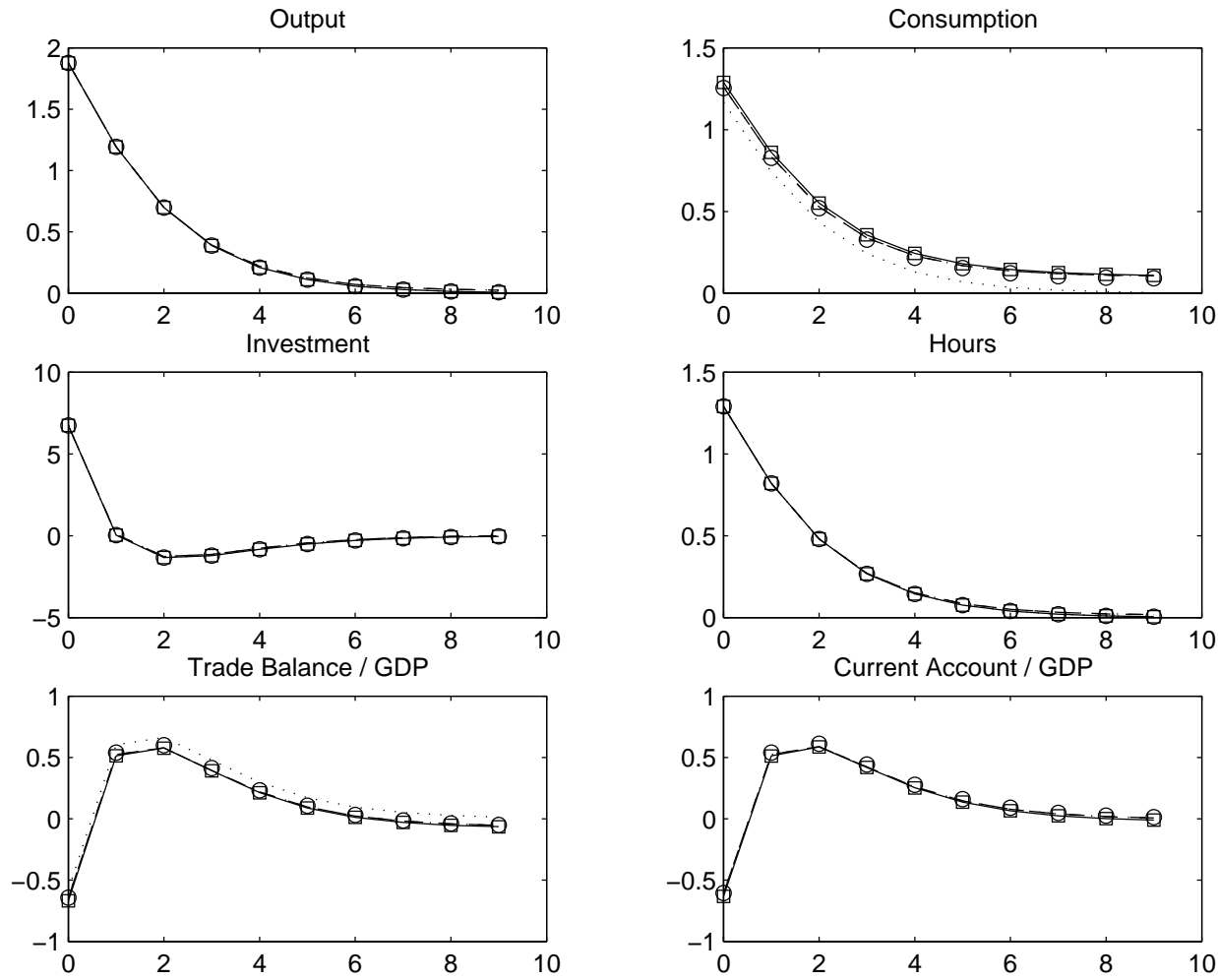

Note. Solid line: Endogenous discount factor model; Squares: Endogenous discount factor model without internalization; Dashed line: Debt-elastic interest rate model; Dash-dotted line: Portfolio adjustment cost model; Dotted line: complete asset markets model; Circles: Model without stationarity inducing elements. 
Table 3: Observed and Implied Second Moments

\begin{tabular}{lcccccc}
\hline \hline & Data & Model 1 & Model 1a & Model 2 & Model 3 & Model 4 \\
\hline Volatilities: & & & & & & \\
$\operatorname{std}\left(y_{t}\right)$ & 2.8 & 3.1 & 3.1 & 3.1 & 3.1 & 3.1 \\
$\operatorname{std}\left(c_{t}\right)$ & 2.5 & 2.3 & 2.3 & 2.7 & 2.7 & 1.9 \\
$\operatorname{std}\left(i_{t}\right)$ & 9.8 & 9.1 & 9.1 & 9 & 9 & 9.1 \\
$\operatorname{std}\left(h_{t}\right)$ & 2 & 2.1 & 2.1 & 2.1 & 2.1 & 2.1 \\
$\operatorname{std}\left(\frac{t b_{t}}{y_{t}}\right)$ & 1.9 & 1.5 & 1.5 & 1.8 & 1.8 & 1.6 \\
$\operatorname{std}\left(\frac{c a_{t}}{y_{t}}\right)$ & & 1.5 & 1.5 & 1.5 & 1.5 & \\
Serial Correlations $:$ & & & & & \\
$\operatorname{corr}\left(y_{t}, y_{t-1}\right)$ & 0.61 & 0.61 & 0.61 & 0.62 & 0.62 & 0.61 \\
$\operatorname{corr}\left(c_{t}, c_{t-1}\right)$ & 0.7 & 0.7 & 0.7 & 0.78 & 0.78 & 0.61 \\
$\operatorname{corr}\left(i_{t}, i_{t-1}\right)$ & 0.31 & 0.07 & 0.07 & 0.069 & 0.069 & 0.07 \\
$\operatorname{corr}\left(h_{t}, h_{t-1}\right)$ & 0.54 & 0.61 & 0.61 & 0.62 & 0.62 & 0.61 \\
$\operatorname{corr}\left(\frac{t b_{t}}{y_{t}}, \frac{t b_{t-1}}{y_{t-1}}\right)$ & 0.66 & 0.33 & 0.32 & 0.51 & 0.5 & 0.39 \\
$\operatorname{corr}\left(\frac{c a_{t}}{y_{t}}, \frac{c a_{t-1}}{y_{t-1}}\right)$ & & 0.3 & 0.3 & 0.32 & 0.32 & \\
$\operatorname{Correlations~with~}$ Output: & & & & & \\
\hline $\operatorname{corr}\left(c_{t}, y_{t}\right)$ & 0.59 & 0.94 & 0.94 & 0.84 & 0.85 & 1 \\
$\operatorname{corr}\left(i_{t}, y_{t}\right)$ & 0.64 & 0.66 & 0.66 & 0.67 & 0.67 & 0.66 \\
$\operatorname{corr}\left(h_{t}, y_{t}\right)$ & 0.8 & 1 & 1 & 1 & 1 & 1 \\
$\operatorname{corr}\left(\frac{t b_{t}}{y_{t}}, y_{t}\right)$ & -0.13 & -0.012 & -0.013 & -0.044 & -0.043 & 0.13 \\
$\operatorname{corr}\left(\frac{c a_{t}}{y_{t}}, y_{t}\right)$ & & 0.026 & 0.025 & 0.05 & 0.051 & \\
\hline \hline
\end{tabular}

Note. The first column was taken from Mendoza (1991). Standard deviations are measured in percent per year.

to a technology shock. Each panel shows the impulse response of a particular variable in the six models. For all variables but consumption and the trade-balance-to-GDP ratio, the impulse response functions are so similar that to the naked eye the graph appears to show just a single line. Again, the only small but noticeable difference is given by the responses of consumption and the trade-balance-to-GDP ratio in the complete markets model. In response to a positive technology shock, consumption increases less when markets are complete than when markets are incomplete. This in turn, leads to a smaller decline in the trade balance in the period in which the technology shock occurs.

\section{Sensitivity Analysis}

\subsection{Alternative Preference Specification}

Thus far, the analysis has focused on a specification of preferences that implies that the labor supply is unaffected by variations in household wealth. This type of preferences is commonplace in 
models of the small open economy. Nevertheless, it is of interest to investigate the extent to which the results reported above are robust to the introduction of preferences implying a wealth effect in labor supply. To this end, we consider a period utility function of the form

$$
U(c, h)=\frac{\left[c^{\omega}(1-h)^{1-\omega}\right]^{1-\gamma}-1}{1-\gamma} .
$$

Under these preferences, the marginal rate of substitution between consumption and leisure is given by

$$
-\frac{U_{h}(c, h)}{U_{c}(c, h)}=\frac{1-\omega}{\omega} \frac{c}{1-h} .
$$

This marginal rate of substitution depends on the level of consumption, whereas that implied by the previously considered preferences does not.

For models featuring an endogenous discount factor (models 1 and 1a), we now assume that

$$
\beta(c, h)=\left[1+c^{\omega}(1-h)^{1-\omega}\right]^{-\psi_{1}} .
$$

We set the parameter $\omega$ at a value consistent with a steady-state value of $h$ of 0.2 . This value for steady-state hours is commonly used in the real-business-cycle literature and implies that households allocate on average twenty percent of their time to the labor market. As in Mendoza (1991), we assume that the steady-state trade-balance-to-GDP ratio is 2 percent. This long-run restriction pins down the parameter $\psi_{1}$ in models 1 and 1a, the parameter $\bar{d}$ in models 2 and 3 , the steady state level of consumption in model 4 , and the initial wealth position in model 5 . We set the parameters $\psi_{2}$ and $\psi_{3}$ in models 2 and 3 so as to capture the observed volatility of the Canadian current-account-to-gdp ratio. Finally, as before, the standard deviation of the productivity shock is set so as to match the observed volatility of Canadian GDP and the adjustment cost parameter $(\phi)$ is set so as to match the standard deviation of Canadian investment. All other parameter values are those used earlier. Table 4 summarizes the calibration of the model.

Table 4: Wealth Elastic Labor Supply: Calibration

\begin{tabular}{|c|c|c|c|c|c|c|c|c|}
\hline$\gamma$ & $\omega$ & $\psi$ & $\alpha$ & $\phi$ & $r$ & $\delta$ & $\rho$ & $\sigma_{\epsilon}$ \\
\hline 2 & 0.22 & $\begin{array}{c}\psi_{1}=0.08 \\
\psi_{2}=\psi_{3}=0.001\end{array}$ & 0.32 & 0.084 & 0.04 & 0.1 & 0.42 & 0.0103 \\
\hline
\end{tabular}

Table 5 and figure 2 present a comparison of unconditional second moments and impulse responses implied by the five models under the new preference specification. Overall, the match between the model and the data is worse than under the baseline preference specification. More relevant for the purpose of this paper is the fact that, as in the case in which labor supply is independent of wealth, models 1 through 4 behave quite similarly. The only noticeable difference is again introduced by the behavior of consumption in the complete asset market model. ${ }^{5}$

\subsection{Stationarity and Speed of Convergence}

The modifications to the standard small open economy model studied in this paper induce stationarity. That is, they eliminate the unit root in net foreign assets and consumption. But these stationarity-inducing mechanisms also affect the speed with which the economy is expected to revert

\footnotetext{
${ }^{5}$ The perfect correlation between consumption and output in model 4 would disappear if shocks to the external marginal utility of consumption were present.
} 
Figure 2: Wealth-Elastic Labor Supply: Impulse Response to a Unit Technology Shock in Models $1-5$
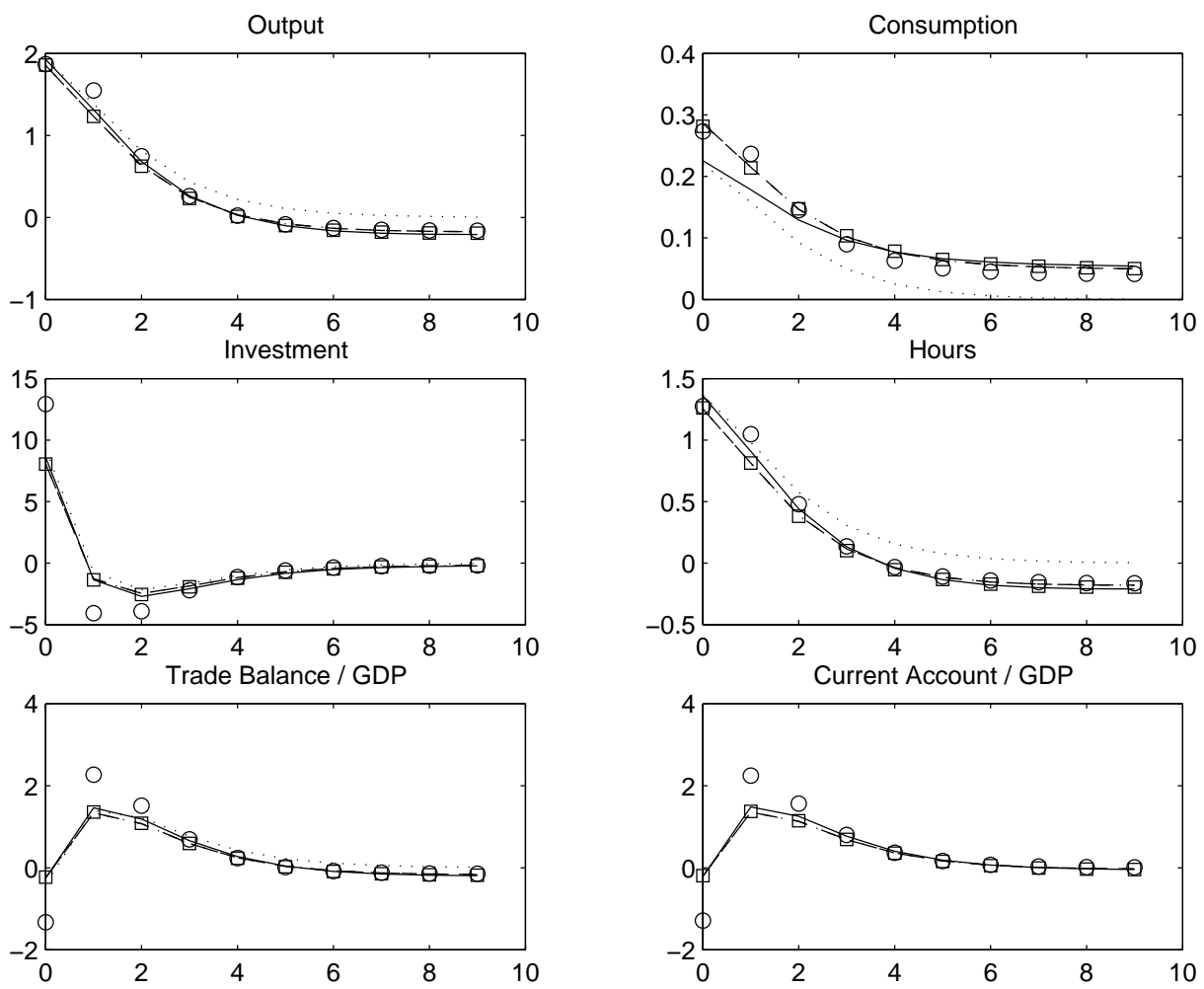

Note. Solid line: Endogenous discount factor model; Squares: Endogenous discount factor model without internalization; Dashed line: Debt-elastic interest rate model; Dash-dotted line: Portfolio adjustment cost model; Dotted line: complete asset markets model; Circles: Model without stationarity inducing elements. 
Table 5: Wealth-Elastic Labor Supply: Observed and Implied Second Moments

\begin{tabular}{lcccccc}
\hline \hline & Data & Model 1 & Model 1a & Model 2 & Model 3 & Model 4 \\
\hline Volatilities: & & & & & & \\
$\operatorname{std}\left(y_{t}\right)$ & 2.8 & 2.9 & 2.7 & 2.7 & 2.7 & 2.6 \\
$\operatorname{std}\left(c_{t}\right)$ & 2.5 & 0.5 & 0.52 & 0.56 & 0.56 & 0.3 \\
$\operatorname{std}\left(i_{t}\right)$ & 9.8 & 9.9 & 9.2 & 9.2 & 9.2 & 10 \\
$\operatorname{std}\left(h_{t}\right)$ & 2 & 2.2 & 2 & 2.1 & 2.1 & 1.9 \\
$\operatorname{std}\left(\frac{t b_{t}}{y_{t}}\right)$ & 1.9 & 2.5 & 2.2 & 2.3 & 2.3 & 2.2 \\
$\operatorname{std}\left(\frac{c a_{t}}{y_{t}}\right)$ & & 2.2 & 2.1 & 2 & 2 & \\
$\operatorname{Serial}$ Correlations: & & & & & \\
$\operatorname{corr}\left(y_{t}, y_{t-1}\right)$ & 0.61 & 0.69 & 0.67 & 0.69 & 0.68 & 0.65 \\
$\operatorname{corr}\left(c_{t}, c_{t-1}\right)$ & 0.7 & 0.88 & 0.82 & 0.84 & 0.84 & 0.65 \\
$\operatorname{corr}\left(i_{t}, i_{t-1}\right)$ & 0.31 & 0.038 & 0.028 & 0.026 & 0.025 & 0.009 \\
$\operatorname{corr}\left(h_{t}, h_{t-1}\right)$ & 0.54 & 0.74 & 0.72 & 0.75 & 0.75 & 0.65 \\
$\operatorname{corr}\left(\frac{t b_{t}}{y_{t}}, \frac{t b_{t-1}}{y_{t-1}}\right)$ & 0.66 & 0.69 & 0.67 & 0.69 & 0.69 & 0.57 \\
$\operatorname{corr}\left(\frac{c a_{t}}{y_{t}}, \frac{c a_{t-1}}{y_{t-1}}\right)$ & & 0.64 & 0.63 & 0.63 & 0.63 & \\
$\operatorname{Correlations}$ with Output: & & & & & \\
$\operatorname{corr}\left(c_{t}, y_{t}\right)$ & 0.59 & 0.25 & 0.42 & 0.32 & 0.34 & 1 \\
$\operatorname{corr}\left(i_{t}, y_{t}\right)$ & 0.64 & 0.53 & 0.54 & 0.54 & 0.54 & 0.57 \\
$\operatorname{corr}\left(h_{t}, y_{t}\right)$ & 0.8 & 0.98 & 0.98 & 0.98 & 0.98 & 1 \\
$\operatorname{corr}\left(\frac{t b_{t}}{y_{t}}, y_{t}\right)$ & -0.13 & 0.61 & 0.59 & 0.61 & 0.61 & 0.49 \\
$\operatorname{corr}\left(\frac{c a t}{y_{t}}, y_{t}\right)$ & & 0.5 & 0.49 & 0.48 & 0.48 & \\
\hline \hline
\end{tabular}

Note. The first column was taken from Mendoza (1991). Standard deviations are measured in percent per year.

to the steady state in response to stationary shocks. In the remainder of this section we explore the connection between stationarity and mean reversion. We begin by studying a simple economy that whose linearized equilibrium conditions can be solved analytically. We then perform a quantitative analysis using the fully fledged IRBC framework presented above.

Consider a small, open, endowment economy populated by a large number of identical households with preferences given by

$$
\begin{gathered}
E_{0} \sum_{t=0}^{\infty} \theta_{t} \ln c_{t} \\
\theta_{0}=1 \\
\theta_{t+1}=\beta\left(\tilde{c}_{t}\right) \theta_{t},
\end{gathered}
$$

where $\theta_{t}$ denotes the discount factor, $c_{t}$ denotes consumption in period $t$, and $E_{0}$ is the mathematical expectation operator given information at time 0 . The discount factor is assumed to depend on the average per capita level of consumption, $\tilde{c}_{t}$, which the representative household takes as given. 
The household faces a period-by-period budget constraint of the form

$$
d_{t}=(1+r) d_{t-1}+c_{t}-y_{t}
$$

where $d_{t}$ denotes foreign debt, $r$ denotes the world interest rate, and $y_{t}$ denotes the endowment income. Income is assumed to follow a first-order autoregressive process

$$
\left(y_{t+1}-\bar{y}\right)=\rho\left(y_{t}-\bar{y}\right)+\epsilon_{t+1} ; \quad \rho \in(-1,1),
$$

where $\epsilon_{t}$ distributes $\operatorname{NIID}\left(0, \sigma^{2}\right)$. In each period $t \geq 0$, households are subject to the following no-Ponzi-game constraint:

$$
\lim _{j \rightarrow \infty} E_{t}(1+r)^{-j} d_{t+j} \leq 0
$$

The household chooses $c_{t}$ and $d_{t}$ so as to maximize (36) subject to the period-by-period budget constraint (37) and the no-Ponzi-game condition (39). The first-order conditions associated with the household's maximization problem are (37), (39) holding with equality, and

$$
\frac{1}{c_{t}}=(1+r) \beta\left(\tilde{c}_{t}\right) E_{t} \frac{1}{c_{t+1}} \text {. }
$$

In equilibrium we have that $\tilde{c}_{t}=c_{t}$. Assume the following functional form for the discount factor

$$
\beta\left(c_{t}\right)=\frac{\left(1+c_{t}-\bar{c}\right)^{-\psi}}{1+r} ; \quad \psi \geq 0,
$$

where $\bar{c}$ is some positive constant. Then a competitive equilibrium is a pair of stochastic processes $\left\{c_{t}, d_{t}\right\}$ satisfying (37), (39) holding with equality, and

$$
\frac{1}{c_{t}}=\left(1+c_{t}-\bar{c}\right)^{-\psi} E_{t} \frac{1}{c_{t+1}}
$$

given $d_{-1}$ and the exogenous stochastic process for the endowment defined in equation (38). Let $\bar{d}=(\bar{y}-\bar{c}) / r$. If $\psi>0$, the pair $\{\bar{c}, \bar{d}\}$ is the non-stochastic steady state of the economy. Note that the steady state is independent of initial conditions, so that the expected long-run levels of foreign debt and consumption are also independent of the initial stock of foreign debt. In this sense, the model is stationary. Linearizing the equilibrium conditions and the endowment process around the point $\{\bar{c}, \bar{y}, \bar{d}\}$ yields

$$
\begin{aligned}
E_{t} \hat{c}_{t+1} & =(1-\psi \bar{c}) \hat{c}_{t} \\
\hat{d}_{t} & =(1+r) \hat{d}_{t-1}+\hat{c}_{t}-\hat{y}_{t} \\
E_{t} \hat{y}_{t+1} & =\rho \hat{y}_{t}
\end{aligned}
$$

where $\hat{x}_{t} \equiv x_{t}-\bar{x}$. This is a system of three linear expectational difference equations with two predetermined variables, foreign debt and the endowment. The non-explosive solution to this system is

$$
\begin{aligned}
& \hat{d}_{t}=(1-\psi \bar{c}) \hat{d}_{t-1}-\frac{1-\rho}{r+\psi \bar{c}+1-\rho} \hat{y}_{t} \\
& \hat{c}_{t}=-(r+\psi \bar{c}) \hat{d}_{t-1}+\frac{r+\psi \bar{c}}{r+\psi \bar{c}+1-\rho} \hat{y}_{t}
\end{aligned}
$$

If $\psi=0$, the equilibrium law of motion of net foreign debt displays a unit root. In this case the discount factor is constant and equal to $1 /(1+r)$. The expected long-run level of foreign debt 
Figure 3: Endowment Economy: Impulse Response to a Unit Output Shock
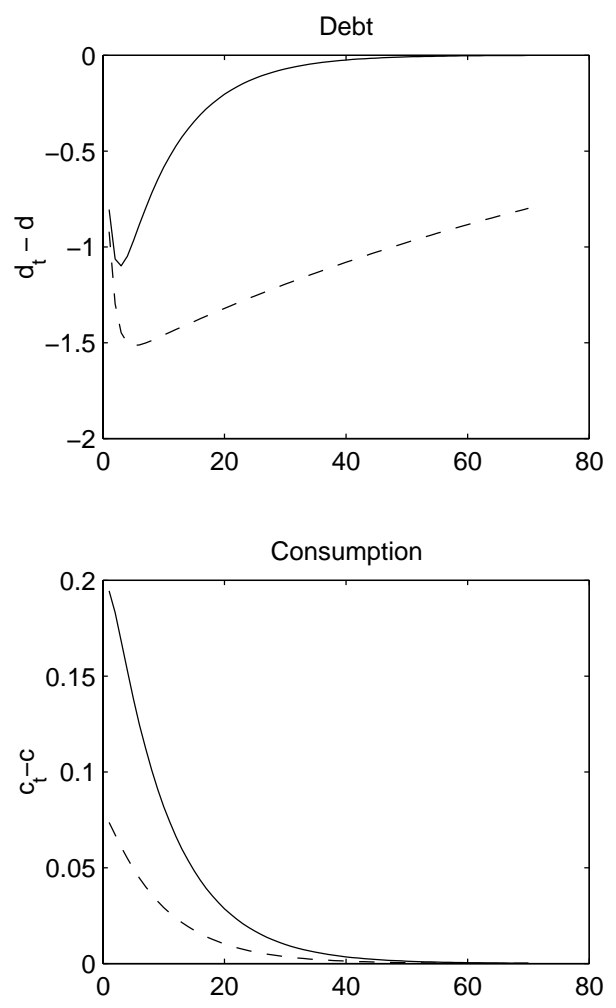

Note. Solid line: $\psi=0.1$; Dashed line: $\psi=0.01$. The values assigned to the remaining structural parameters are: $r=0.04, \bar{c}=1$, and $\rho=0.42$.

given information at time 0 is $\lim _{t \rightarrow \infty} E_{0} d_{t}=d_{-1}-1 /(r+1-\rho) \hat{y}_{0}$. This implies that the expected long-run level of foreign debt (and with it consumption) depends on the initial level of foreign debt and the initial realization of the endowment shock. Therefore, temporary shocks have permanent effects on the level of consumption and foreign debt. In this sense the model is non-stationary. Local approximation techniques are therefore invalid.

For positive values of $\psi$ that are close to 0 , the coefficient on $\hat{d}_{t-1}$ in the equation giving the evolution of $\hat{d}_{t}$ is less than one and thus the equilibrium process for external debt is mean reverting. Moreover, the speed of mean reversion increases with the value of $\psi$. Also in response to innovations in output the change in $d_{t}$ is smaller the larger is $\psi$. Similarly, the speed of mean reversion in consumption is also enhanced by higher values of $\psi$. However, the initial impact of an output shock on consumption is larger the larger is $\psi$. The intuition behind these results is simple. In this economy agents become more impatient as consumption increases. Thus, as the elasticity of the discount factor increases, they are willing to trade off a higher impact effect of an output shock on consumption for a faster return to the steady state. Figure 3 illustrates this trade-off. It depicts the impulse response of debt and consumption to a unit innovation in output in period 1 for two alternative values of the parameter $\psi$ measuring the sensitivity of the discount factor with respect to consumption.

To illustrate how the parameters determining stationarity affect the speed of mean reversion in the context of a more realistic model with endogenous labor supply and capital accumulation, we 
Figure 4: Stationarity and Speed of Convergence: Impulse Responses of Model 2 to a Productivity Shock
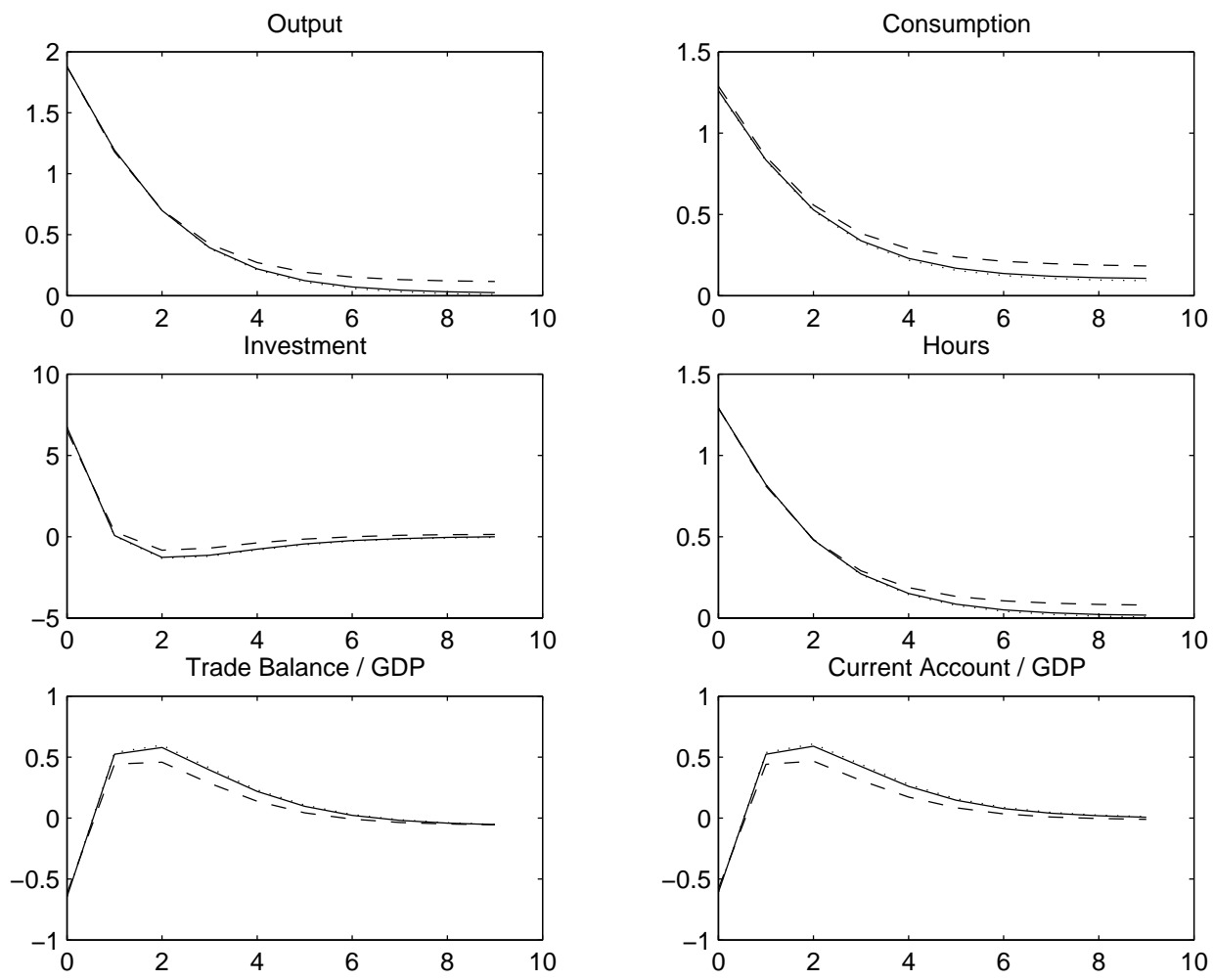

Note. Solid line: $\psi_{2}=$ baseline value; Dashed line: $\psi_{2}=$ ten times the baseline value; Dotted line: $\psi_{2}=$ one tenth the baseline value;

plot in figure 4 the impulse response of model 2 (debt elastic interest rate) to a productivity shock for alternative values of $\psi_{2}$, measuring the elasticity of the country premium with respect to foreign debt. We consider three different values of $\psi_{2}: 0.000742$ (the baseline value), $0.000742 \times 10$, and $0.000742 / 10$. It is evident from the figure that altering this parameter within a wide range around the baseline value does not affect the quantitative predictions of the model in significant ways. We do not choose models 1 or 1a (endogenous discount factor) for this sensitivity analysis because in these models the parameter $\psi_{1}$, governing the stationarity of the model, also affects the steady-state level of consumption and external debt. This problem does not arise in the simple version of model 1a considered above in this section. In that model, consumption and net foreign debt appear to be more sensitive to wide variations in the parameter $\psi$ controlling the stationarity of the model (see figure 3). Of course, although both $\psi$ and $\psi_{2}$ determine the stationarity of their respective models, changes in their calibrated values are not directly comparable. Performing the sensitivity analysis with model 3 (portfolio adjustment costs) delivers identical results to those presented in figure 4 . Finally, model 4 (complete asset markets) does not feature a parameter governing stationarity, and thus it does not lend itself to the type of sensitivity analysis conducted here. 


\section{Conclusion}

In this paper, we present five alternative ways of making the small open economy real business cycle model stationary: two versions of an endogenous discount factor, a debt-contingent interest rate premium, portfolio adjustment costs, and complete asset markets. The main finding of the paper is that once all five models are made to share the same calibration, their quantitative predictions regarding the behavior of key macroeconomic variables, as measured by unconditional second moments and impulse response functions, is virtually identical. We conclude that if the reason for modifying the canonical nonstationary small open economy model in any of the ways presented in the present study is simply technical, that is, solely aimed at introducing stationarity so that the most commonly used numerical approximation methods can be applied and unconditional second moments can be computed, then in choosing a particular modification of the model the researcher should be guided by computational convenience. In other words, the researcher should choose the variant of the model he finds easiest to approximate numerically. In this respect model 1, featuring an endogenous discount factor a la Uzawa (1968) is in disadvantage vis a vis the other models. For its equilibrium conditions contain an additional state variable.

A second result of our paper is that, in line with results previously obtained in the context of two-country real-business-cycle models by Kollmann (1996) and Baxter and Crucini (1995), whether asset markets are complete or incomplete makes no significant quantitative difference.

This paper could be extended in several dimensions. One would be to allow for additional sources of uncertainty, such as domestic demand shocks (i.e., government purchases and preference shocks) and external shocks (i.e., terms-of-trade and world-interest-rate shocks). A second possible extension is to consider other characteristics of the business cycle along which to compare the various models, such as frequency decompositions. Finally, one could study additional stationarity induces variations of the small open economy model. For example, Cardia (1991) and Ghironi (2001) among others bring about stationarity by introducing overlapping generations with perpetually young agents á la Blanchard (1985). 


\section{References}

Baxter, Marianne and Crucini, Mario J., "Business Cycles and the Asset Structure of Foreign Trade," International Economic Review 36, November 1995, 821-54.

Blanchard, Olivier, "Debt, Deficits, and Finite Horizons," Journal of Political Economy 93, 1985, 223-247.

Cardia, Emanuela, "The Dynamics of a Small Open Economy in Response to Monetary, Fiscal, and Productivity Shocks," Journal of Monetary Economics 28, 1991, 411-434.

Correia, Isabel, João C.Neves, and Sergio Rebelo, "Business Cycles in a Small Open Economy," European Economic Review 39, 1995, 1089-1113.

Ghironi, Fabio, "Macroeconomic Interdependence under Incomplete Markets," manuscript, Boston College, October 2001.

Kim, Sunghyun Henry and Ayhan Kose, "Dynamics of Open Economy Business Cycle Models: Understanding the Role of the Discount Factor," Tufts University, 2001, forthcoming, Macroeconomic Dynamics.

Kollmann, Robert, "Incomplete Asset Markets and the Cross-Country Consumption Correlation Puzzle," Journal of Economic Dynamics and Control 20, May 1996, 945-61.

Mendoza, Enrique, "Real Business cycles in a small-open economy," American Economic Review 81, 1991, 797-818.

Mendoza, Enrique and Martín Uribe, "Devaluation Risk and the Business-Cycle Implications of Exchange-Rate Management," Carnegie-Rochester Conference Series on Public Policy 53, December 2000, 239-96.

Neumeyer, Pablo A. and Fabrizio Perri, "Business Cycles in Emerging Markets:The Role of Interest Rates," manuscript, New York University, May 2001.

Obstfeld, Maurice, "Intertemporal dependence, impatience, and dynamics," Journal of Monetary Economics 26, 1990, 45-75.

Schmitt-Grohé, Stephanie, "The international transmission of economic fluctuations: Effects of U.S. business cycles on the Canadian economy," Journal of International Economics 44, April 1998, 257-287.

Schmitt-Grohé, Stephanie and Martín Uribe, "Stabilization Policy and the Costs of Dollarization," Journal of Money, Credit, and Banking 33, May 2001, 482-509.

Senhadji, Abdelhak S., "Adjustment of a Small Open Economy to External Shocks," Dissertation, University of Pennsylvania, 1994.

Uribe, Martín, "Exchange rate based inflation stabilization: the initial real effects of credible plans," Journal of Monetary Economics 39, 1997, 197-221.

Uzawa, H., "Time preference, the consumption function and optimum asset holdings," in Wolfe, J.N. (Ed.), Value, Capital and Growth: Papers in Honor of Sir John Hicks, The University of Edinburgh Press, Edinburgh, 1968, pp. 485-504. 